\title{
Study of Causes of Otalgia in Ear and Non-Ear Diseases
}

\section{IJCRR}

Section: Healthcare

ISI Impact Factor

(2019-20): 1.628

IC Value (2019): 90.81

$\operatorname{SJIF}(2020)=7.893$

(c) (7) (8)

Copyright@IJCRR

\section{Bryan Joel Devaraj ${ }^{1}$, Meenakshi M${ }^{1}$, Deepak Raj K ${ }^{\mathbf{1}}$}

\begin{abstract}
'3 $3^{\text {rd }}$-year MBBS, Department of Otorhinolaryngology, Saveetha Medical College and Hospital, Saveetha Nagar, Thandalam, Chennai-602105, Tamil Nadu, India; ${ }^{2}$ Post-graduate, Department of Otorhinolaryngology, Saveetha Medical College and Hospital, Saveetha Nagar, Thandalam, Chennai-602105, Tamil Nadu, India; ${ }^{3}$ Senior Resident, Department of Otorhinolaryngology, Saveetha Medical College and Hospital, Saveetha Nagar, Thandalam, Chennai-602105, Tamil Nadu, India.
\end{abstract}

\section{ABSTRACT}

Introduction: Otalgia is defined as ear pain, it is one of the most common complaints with which a patient presents to ENT OPD or emergency department

Aims and Objectives: To identify causes of otalgia in the ear and non-ear diseases in patients visiting the ENT OPD of Saveetha Medical College and Hospital in Tamilnadu, India.

Methodology: The study was conducted on 40 patients who visited the ENT OPD of Saveetha Medical College and Hospital with an earache. Patient's details such as age, sex, complaint, causes and physical finding were recorded in an excel sheet and. The study tools used in the study are clinical examination and investigations.

Result: The leading cause of otalgia was found to be non-ear diseases (60\%) from the study done on 40 patients with an earache in the ENT OPD of Saveetha Medical College and Hospital. Dental pain was the leading cause and was to be the cause in males predominantly over females by three times. Otitis externa was the leading cause of ear diseases followed by acute otitis media, chronic suppurative otitis media and by impacted wax.

Conclusion: Since the last century there have been many studies to show the non-ear causes of otalgia which is caused by referred pain from other sites which are connected with the ear by different nerves, Since classifying the cases of otalgia as those caused by ear and non-ear-diseases will help in the assessment and treatment of the pain.

Key Words: Primary otalgia, Classification of otalgia, Observational study, Ear pain, Causes of otalgia, Non-ear causes of otalgia, Referred pain

\section{INTRODUCTION}

Otalgia is defined as ear pain, it is one of the most common complaints with which a patient presents to ENT OPD or emergency department. There are two distinct types of otalgia, primary otalgia where the underlying pathology is in the ear and secondary otalgia where the underlying cause is elsewhere. The origin of pain may be in the ear, structures around the ear or other head and neck structures. This is due to the complex nervous connections in the head and neck areas, the ear, the pharynx and the nose. ${ }^{1}$ The primary causes of otalgia are often benign and can be easily identified on examination such as trauma, infection, lodging of foreign bodies, otitis media, otitis externa, acute otitis media, discharge and primary neoplasms which can be identified through otoscopy. The secondary causes of otalgia are considered only when the cause is not obvious and cannot be identified by primary investigations, these causes include barotrauma, dental inflammation and infection, temporomandibular joint disorders, trigeminal neuralgia, head and neck cancers, arytenoid arthritis. Certain grave diseases such as temporal arteritis and malignant neoplasms present as ear pain. ${ }^{1,2}$

\section{Objective:}

- To find the most common cause of ear pain in ear pathology

- To find the most common cause of ear pain in non-ear pathology

\section{Methodology}

It is an observational study conducted in 2020 on 40 patients who visited the ENT OPD of Saveetha Medical College and Hospital with an earache after obtaining Institutional ethical committee clearance(SMC/IEC/2020/03/321). Those

\section{Corresponding Author:}

Dr. Meenakshi M, Post-graduate, Department of Otorhinolaryngology, Saveetha Medical College and Hospital, Thandalam, Chennai-602105, India; Contact: +91 63829-02873; Email: meenumuthiah1995@gmail.com

ISSN: $2231-2196$ (Print)

Received: 17.09 .2020
ISSN: 0975-5241 (Online)

Revised: 23.11 .2020
Accepted: 03.02 .2021
Published: 20.07 .2021 
patients with a previous history of head and neck surgeries were excluded from the study. All patients underwent thorough ENT examination, head and neck examination and investigation to find the cause of their otalgia. The patient's details such as age, sex, complaints, findings from examination and investigations and the cause of otalgia were all recorded in an excel sheet and tabulated.

\section{RESULTS}

In the ENT OPD of Saveetha Medical College and Hospital in 2020, 40 patients with otalgia were studied. The causes of otalgia were diagnosed and were categorized into non-ear diseases and ear diseases it was found that most common cause of otalgia is non ear pathology, 60\% (24) cases. The ear causes of otalgia were about 40\% (16) cases (Figure 1).

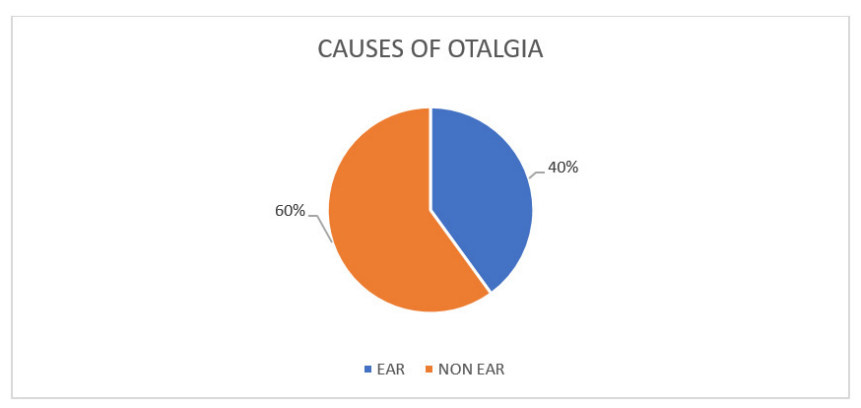

Figure 1: Causes of otalgia among the study participants.

These non-ear cases were referred to other departments for a thorough examination and confirmation of the cause of otalgia. The most frequent non-ear causes were toothache $(20 \%)$ with male dominance in the cases with a ratio of $3: 1$, followed by cervical spine lesions $(12.5 \%)$ with the cause being more frequent in women with a ratio of $4: 1$, followed by TMJ arthritis and tonsilitis (10\%) both with an equal number of cases in both sexes in the prior and a male dominance seen in the latter, pharyngitis $(5 \%)$ is seen in equal numbers in both sexes and the least cause being carcinoma of larynx $(2.5 \%)$ (Table I).

Table I: Non-ear causes of otalgia among the study participants.

\begin{tabular}{lcccc} 
Non Ear Causes & Incidence & Male & Female & $\begin{array}{c}\text { Male } \\
\text { Female } \\
\text { Ratio }\end{array}$ \\
Dental & $20 \%$ & 6 & 2 & $3: 1$ \\
TMJ (Temporo- & $10 \%$ & 2 & 2 & $1: 1$ \\
mandibular joint) & & & & \\
Arthritis & $12.5 \%$ & 1 & 4 & $1: 4$ \\
Cervical Spine Le- & $10 \%$ & 3 & 1 & $3: 1$ \\
sions & $5 \%$ & 1 & 1 & $1: 1$ \\
Tonsillitis & $2.5 \%$ & 1 & 0 & nil \\
Pharyngitis & & & & \\
Cancer Larynx & & & & \\
\hline
\end{tabular}

The major cause among ear diseases was otitis externa (30\%) followed by acute otitis media (25\%) and chronic suppurative otitis media (25\%) and impacted wax (20\%) being the least cause in patients with earache (Figure 2).

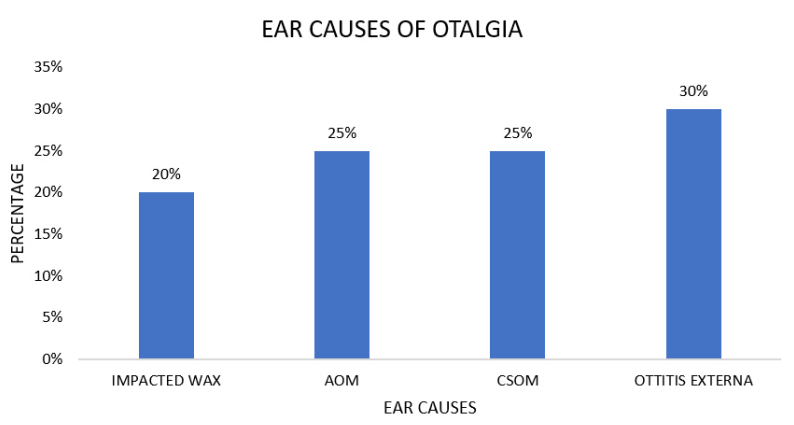

Figure 2: Ear causes of otalgia among the study participants.

\section{DISCUSSION}

Otalgia is one of the most uncomfortable experiences for all age groups making them seek the doctor in almost all cases. This is due to the complex innervation of the ear. The outer, middle and internal ear are all complex and small structures that are very sensitive. ${ }^{2}$ In our study, $55 \%$ of patients with ear pain, the pain was caused by non-ear diseases which is much less than the study conducted by Mohammed et al, where among 770 patients suffering from otalgia, 12.2\% had the referred type of pain. ${ }^{3}$ In this study non-ear causes of otalgia are seen more in men (55\%) than in women (45\%) which is consistent with the Kiakojoori et al. study which is of $60 \%$ men and $40 \%$ women. ${ }^{4}$ In our study the most prevalent cause is dental $(20 \%)$ which is following study by Mohammed et al. ${ }^{3}$ In a study conducted by Kim et al., toothache was accounted for as the most common cause of referred otalgia. ${ }^{5}$ In a study conducted by Zhraa et al. the second most frequent nerve pathways to cause secondary otalgia is cervical spine lesions $(24.3 \%)$ which is consistent with our findings where cervical spine lesion causes referred otalgia in $12.5 \%$ of the cases. ${ }^{6}$ In Behnoud et al study the most common cause is a temporomandibular joint which is against our study where it causes referred otalgia in $10 \%$ of the cases. ${ }^{3}$ In our study there is one case of carcinoma which is consistent with the study conducted by Reiter et al. which reports a case of carcinoma manifesting as a non-ear disease cause of otalgia. In a study conducted by Mulwafu et al. among 17 patients with carcinoma, $33 \%$ of the cases suffered from referred otalgia. In a study conducted by Mohammed et al., $1 \%$ of the nonear cause of referred otalgia was due to carcinoma which is lesser than our study with $2.5 \%$ of the cases. ${ }^{2}$ In a Similar study by Neilan et alpatients presenting with otalgia posting diagnostic challenges, undergo a detailed history and examination to find the aetiology to be secondary causes of otalgia 
as seen in our study. ${ }^{8}$ Referred otalgia has been a well-known condition of the ear since early 1910 . The results from our study are similar to another study conducted by Chen et al., which shows that in recent decades the development of CT and MRI technology has helped in identifying the cervical lesions causing otalgia which contributes to about $12.5 \%$ of the cases. ${ }^{9}$ In our study $10 \%$ of the cases are due to TMJ disorder caused otalgia, due to the affected complex synovial system, articulating ligaments and masticatory muscles which in par goes with a study done by Shalender Sharma et al. ${ }^{10}$

\section{CONCLUSION}

In this study, it is seen that non-ear diseases are the leading cause of otalgia than ear diseases. Thus, making it important to note that dental hygiene has to be checked in patients with otalgia. To diagnose the cause other than dental, different parts sharing the nervous connections are to be examined for identification and confirmation of cause to provide suitable treatment. Simple awareness of ear hygiene and methods to keep the ear clean can bring about a large reduction in the ear causes of otalgia. A thorough diagnostic study of the structures surrounding and in and around the ear required to detect malignancies.

\section{ACKNOWLEDGEMENT}

I would like to thank the faculty of the Department of Otorhinolaryngology of Saveetha Medical College and Hospital for their constant support and guidance in the completion of the research. I would like to thank all others who were involved directly and indirectly in the study and also the patients who participated in the study.

\section{Conflict of interest: Nil}

Source of funding: Nil

\section{Authors contribution:}

Bryan Joel Devaraj- Data collection, Writing the manuscript.
Dr. Meenakshi.M - Data collection, Writing the manuscript, Study design, Final draft correction and review.

Dr. Deepak Raj. K- Writing the manuscript, Study design, Final draft correction and review.

\section{Abbreviations: \\ ENT- Ear, nose and throat, \\ OPD- Outpatient department}

\section{Key points:}

- $60 \%$ of the study participants had a non-ear pathology that caused the otalgia and $40 \%$ had an ear pathology that caused the otalgia.

- Otitis externa is the most common ear pathology that caused otalgia among the study participants.

- The most frequent non-ear cause of otalgia was toothache.

\section{REFERENCES}

1. Ely JW, Hansen MR, Clark EC. Diagnosis of ear pain. Am Fam Phys. 2008 Mar 1;77(5):621-8.

2. Siddapur GK, Siddapurkr. Clinical profile of referred otalgia in a tertiary health centre-a retrospective study. Int J Curr Res Rev. 2014 Jul 22;6(14):17-24.

3. Taziki MH, Behnampour N. A study of the aetiology of referred otalgia. Iranian J Otorhinolar. 2012;24(69):171.

4. kiakojoori K, Tavakoli HR. Cases of referral otalgia in patients referred to Shahid Beheshti clinic Babol 1999. J Babol Univ Med Sci. 2002;5(1):41-3

5. Kim DS, Cheang P, Dover S, Drake-Lee AB. Dental otalgia. J Laryng Oto. 2007 Dec 1;121(12):1129.

6. Taboo ZA, Burma MF. Aetiology of referred otalgia. Iraqi Acad Scient J. 2013;12(3):436-42.

7. Reiter S, Gavish A, Winocur E, Emodi-Periman A, Eli I. Nasopharyngeal carcinoma mimicking a temporomandibular disorder: a case report. J Orofac Pain. 2006 Jan 1;20(1).

8. Neilan RE, Roland PS. Otalgia. Med Clin. 2010 Sep 1;94(5):96171.

9. Chen RC, Khorsandi AS, Shatzkes DR, Holliday RA. The radiology of referred otalgia. Amer J Neurorad. 2009 Nov 1;30(10):1817-23.

10. Sharma S, Gupta DS, Pal US, Jurel SK. Etiological factors of temporomandibular joint disorders. Nat J Maxill Surg. 2011 Jul;2(2):116. 